\title{
Colombia y los flujos mixtos de migrantes en el derecho internacional de los refugiados*
}

\author{
Melina Ocampo González** \\ Sebastián Arboleda Cardona*** \\ Recibido: julio de 2016 \\ Aprobado: octubre de 2016 \\ DOI: 10.22395/ojum.v15n30a4
}

\section{RESUMEN}

Colombia se ha convertido en los últimos años en un país de tránsito para los flujos mixtos de migrantes. Estas dinámicas globales son consecuencia de las necesidades de los individuos de huir de sus países, debido a conflictos internos, violencia generalizada, violaciones masivas a los derechos humanos, persecución de Estado, catástrofes naturales o simplemente la esperanza de mejorar sus condiciones socioeconómicas. Esto ha causado que los migrantes deban acudir a redes internacionales de tráfico de personas cuando no pueden migrar legalmente, porque no cumplen con los requisitos de visado.

Este artículo buscará promover el debate sobre estos asuntos de política pública internacional, a través de la presentación de un diagnóstico sobre la situación actual de los flujos mixtos de migrantes, el tráfico de personas y la efectiva protección a sus derechos humanos, desde el enfoque del derecho internacional de los refugiados.

Palabras clave: flujos mixtos de migrantes; tráfico de migrantes; necesidad de protección internacional; refugiados; derecho internacional de los refugiados.

Este artículo se deriva del proyecto de investigación "Colombia y los flujos mixtos de migrantes: diagnósti$\mathrm{co}$, necesidades y soluciones duraderas". Esta investigación es financiada por el fondo para el desarrollo de la investigación de la Corporación Universitaria Lasallista.

** Melina Ocampo González es abogada con maestría en Estudios Migratorios de University of Sussex (Inglaterra) y especialista en Seguridad Social. Es docente de tiempo completo del área de Derecho Internacional en la Corporación Universitaria Lasallista e integrante del Grupo de Investigación en Derecho -GRIDE-. Correspondencia: meocampo@lasallistadocentes.edu.co.

** Sebastián Arboleda Cardona es abogado especialista en Derecho Comercial de la Universidad del Rosario, es docente de tiempo completo, director del Consultorio Jurídico de la Corporación Universitaria Lasallista e integrante del Grupo de Investigación en Derecho -GRIDE-. Actualmente está estudiando una Maestría en Propiedad Intelectual y Nuevas Tecnologías en Universidad Internacional de la Rioja. Correspondencia: searboleda@lasallistadocentes.edu.co. 


\section{Colombia and Combined Flows of Migrants in the International Refugee Law}

\section{ABSTRACT}

During the last years, Colombia has become a country of transit for combined flows of migrants. This global dynamic is the result of the needs of individuals for escaping from their countries of origin due to internal conflicts, general violence, massive violation of human rights, State persecution, natural disasters or the simple hope of improving their social and economic conditions. This has forced migrants to resort to international human trafficking networks when they are not able to migrate legally since they are not in compliance with relevant visa clearance requirements.

This article is intended to promote a debate on international public policies, by providing a diagnosis on the current situation of the combined flows of migrants, human trafficking, and the effective protection of their human rights from the point of view of the international refugee law.

Key words: combined flows of migrants; migrants trafficking; international protection need; refugees; international refugee law. 


\section{INTRODUCCIÓN}

En el mundo actual se presenta un aumento en el flujo mixto de migrantes. Durante el 2014, hubo un incremento del 45\% en el número de solicitantes de refugio, y dicha tendencia continuó durante el año 2015, siendo alarmante la migración irregular desde el oriente próximo y África. Con 441.900 aplicaciones de refugio durante 2015, Alemania es el país desarrollado con más solicitudes en el mundo. Es seguido por Estados Unidos (172.700), Suecia (156.400) y la Federación Rusa (152.500) (UNHCR, 2016).

Los 5 países cuyos nacionales realizaron la mayor cantidad de solicitudes de asilo fueron: Siria (158.700 solicitantes), Albania, Serbia y Kosovo (50.100), Afganistán (31.400), Irak (29.800) y Eritrea (10.900) (UNHCR, 2016). En 2015, 1.015.078 migrantes cruzaron el mar Mediterráneo para llegar a Europa, la mayoría provenientes de Siria y Eritrea. Esta cifra es casi 15 veces mayor a la vivida en 2011 durante la Primavera Árabe (70.000) (Frontex, 2015; UNHCR, 2016), y se prevé que siga aumentando durante los próximos años de manera gradual, lo cual posiciona este tema como uno de los principales de la agenda mundial.

Por otra parte, Estados Unidos recibe al 20\% de total de migrantes del mundo, de los cuales un cuarto llega de manera irregular (Population Reference Bureau, 2013). Durante el 2015, este país recibió 172.700 aplicaciones para asilo, con un incremento del 42\% con respecto al 2014 (121.200 aplicaciones) (UNHCR, 2015). La migración de cubanos a Estados Unidos también ha aumentado, con picos en 2013 y 2015. Durante el 2015 ingresaron 43.000 cubanos, lo que significó un incremento del 78\% frente al 2014 (Los Ángeles Times, 2016).

En los últimos años, ha sido notorio un incremento en el número de migrantes cubanos, que buscan también refugiarse en Estados Unidos. En parte, esto se debe a la Ley de Ajuste Cubano para Refugiados de 1966, que les permite obtener el permiso de residencia en EE. UU. después de permanecer un año en este país, sin tener que demostrar su ingreso legal. En 1995 Estados Unidos intentó contrariar sus efectos con la política de Pies mojados/ Pies secos, para desincentivar la llegada de cubanos por vía marítima, prohibiendo la admisión en su territorio de personas que fueran encontrados en el mar. En el mes de diciembre de 2014, el presidente de Estados Unidos, Barack Obama, anunció su intención de regularizar las relaciones diplomáticas con Cuba, rotas desde 1961. Esta declaración disparó en un 60\% la llegada de cubanos a este país, debido a la incertidumbre por un posible cambio de estas políticas y sus beneficios.

En Colombia se ha sentido el impacto de estos flujos migratorios y las necesidades de atención humanitaria para los migrantes en tránsito, especialmente en el municipio de Turbo -Antioquia-, lo cual se reporta constantemente en las notas de prensa ${ }^{1}$. La regla general es la

\footnotetext{
Se referencia algunas recientes: Razonpublica.com. (2016, 8 de agosto). El drama humanitario de los migrantes irregulares, http://www.razonpublica.com/index.
} 
detección de extranjeros que ingresan irregularmente al país, con el objetivo de cruzar hacia Panamá y continuar la ruta que les permitiría llegar a Estado Unidos.

Tradicionalmente, Colombia ha tenido una política migratoria más restrictiva que la de nuestros países vecinos -Panamá, Venezuela, Brasil y Ecuador-, lo que en la

php/economia-y-sociedad/9638-el-drama-humanitario-de-los-migrantes-irregulares.html?utm source $=$ MadMimiEutm medium =email\&utm content $=$ Colombia + en + los + Juegos $+\mathrm{Ol} \% \mathrm{C} 3$ \%ADmpicosEutm campaign $=20160808$ m133410460_Colombia+en+los+Juegos+Ol\% C3\%ADmpicos\&utm _term=Socorro+Ram _ C3_ADrez.

Wradio.com.co. (2016, 8 de septiembre). Más de 100 migrantes irregulares interceptados en Guatemala, http:// www.wradio.com.co/noticias/internacional/masde-100-migrantes-irregulares-interceptados-enguatemala/20160908/nota/3240599.aspx.

Semana.com. (2016, 3 de agosto). Defensoría pide plan de contingencia por deportación de cubanos, http:// www.semana.com/nacion/articulo/deportacion-decubanos-migrantes-necesita-plan-de-contingencia/484467.

Eltiempo.com. (2016, 3 de agosto). Ya hay 84 solicitudes de deportación voluntaria de cubanos en Turbo, http:// www.eltiempo.com/politica/gobierno/deportacionde-cubanos-en-turbo-antioquia/16663711.

Semana.com. (2016, 2 de agosto). Cientos de cubanos encaran la deportación de Colombia en pocos días, http:// www.semana.com/nacion/galeria/migracion-colombia-cubanos-seran-deportados-en-los-proximos-dias/484363.

Semana.com. (2016, 29 de julio). Así funciona el complejo negocio de tráfico de migrantes, http://www.semana. com/nacion/articulo/como-funciona-el-negociode-trafico-de-migrantes-a-colombia/483861.

Elcolombiano.com. (2016, 4 de agosto). Situación de inmigrantes en Turbo es cada vez más tensa, http:// www.elcolombiano.com/antioquia/situacion-deinmigrantes-en-turbo-es-cada-vez-mas-tensaJF4700957.

Elpaís.com.co. (2015, 29 de noviembre). Estas son las rutas del tráfico de migrantes en Colombia, http://www. elpais.com.co/elpais/colombia/noticias/asi-sonrutas-trafico-migrantes-colombia. práctica ha generado que sea un territorio oneroso y peligroso para los migrantes; y ha causado un incremento en los niveles de corrupción, debido a que las personas que no pueden migrar legalmente buscan redes internacionales de traficantes, que les garanticen que podrán llegar a su destino final a través de sus rutas. Adicional a esto, Ecuador y Panamá incrementaron sus controles migratorios durante el año 2016, situación que ha dificultado el tránsito de los flujos mixtos por estos países fronterizos con Colombia.

Este artículo tiene como propósito reflexionar sobre la política migratoria colombiana, a partir de un análisis de contexto realizado en los departamentos de Antioquia y Chocó, y los efectos que esta ha tenido sobre el flujo mixto de migrantes y el respeto por sus derechos humanos, desde el enfoque del derecho internacional de los refugiados. Con este fin, se realizará un análisis del marco jurídico nacional e internacional de protección, las tendencias migratorias nacionales y departamentales, las rutas de tránsito, la red internacional de traficantes, los grupos armados ilegales y los riesgos para los migrantes. Por último, se presentarán unas conclusiones acompañadas con una serie de recomendaciones de medidas internas, que cumplan con las obligaciones internacionales adquiridas por Colombia.

La información que permitió el análisis de contexto en Antioquia y Chocó, sobre la situación de los derechos humanos de los migrantes, fue obtenida en una serie de entrevistas semiestructuradas, con autoridades policiales y militares, y 
con funcionarios de ACNUR y Migración Colombia en la subregión de Urabá y en Medellín.

\section{MARCO JURÍDICO DE PROTECCIÓN INTERNACIONAL Y NACIONAL PARA LOS FLUJOS MIXTOS DE MIGRANTES}

\section{Los mecanismos internacionales y nacionales de protección}

La protección internacional para los migrantes opera mundialmente para los casos de apátridas y personas que argumenten ser perseguidas por razones de raza, religión, nacionalidad, opinión política, o por pertenecer a un determinado grupo social -categoría en continuo desarrollo por la jurisprudencia de tribunales internacionales- (Convención sobre el Estatuto de los Refugiados de 1951, ratificada por Colombia el 10 de octubre de 1961; y su Protocolo de 1967, ratificado por Colombia el 4 de marzo de 1980).

América Latina se ha caracterizado por brindar una protección más amplia a los migrantes, debido a las guerras civiles sufridas en Centroamérica (Gil-Bazo, 2013). Con la Declaración de Cartagena sobre Refugiados de 1984, se añadió una categoría adicional para argumentar la calidad de refugiado, que consiste en "haber huido de sus hogares porque su vida, seguridad o libertad han sido amenazas por violencia generalizada, la agresión extranjera, los conflictos internos, la violación masiva a los derechos humanos $\mathrm{u}$ otras circunstancias que hayan perturbado gravemente el orden público". Esta Declaración tuvo como precedente la Conferencia sobre el Asilo y la Protección Internacional de los Refugiados en América Latina en 1981, la cual creó unas bases sólidas sobre el concepto regional de protección, adoptado en 1984.

La Declaración de Cartagena ha sido objeto de seguimiento (UNHCR, 2004) a través de posteriores instrumentos de similar naturaleza: Declaración y Plan de Acción de México (2010) y Declaración de Brasil sobre la Protección de Personas Refugiadas y Apátridas en el Continente Americano (2010). Estas declaraciones tuvieron como finalidad fortalecer las redes nacionales y regionales de protección y cooperación, y ratificar el espíritu solidario y humano de la declaración de 1984. Por su parte, la Declaración de Brasilia plantea una hoja de ruta para promover la protección e implementación de soluciones duraderas e innovadoras para las personas refugiadas, desplazadas y apátridas, con 11 programas estratégicos que deben ser implementados en los 10 años siguientes a su adopción. La misma fue complementada en 2014 con la Declaración de Brasil para fortalecer la cooperación regional.

Las declaraciones regionales son de derecho suave, "soft law" (Casanovas y Rodrigo, 2012), es decir, que no tienen carácter vinculante por no tener la categoría de tratados internacionales. Sin embargo, al revisar la aplicación en Colombia de estos instrumentos, nos debemos remitir a la Convención Americana que en el artículo 22.7 estipuló: "Toda persona tiene el derecho de buscar y recibir asilo en territorio extranjero [...] de acuerdo con la legislación de cada Estado y los convenios 
internacionales". La citada Convención es de obligatorio cumplimiento en Colombia, por haber sido ratificada el 28 de mayo de 1973.

La legislación interna, para el caso colombiano, es el Decreto 4503 de 2009 , que en su artículo 1 ratifica tanto la definición global que trae el Estatuto para los Refugiados, como la Declaración de Cartagena. Adicional a las categorías plasmadas en la Declaración, el artículo 1, en el numeral (c), expresa que también es refugiado quien tenga razones fundadas para creer que estaría en peligro de ser sometido a tortura en caso de que se procediera a su expulsión, devolución o extradición a su país de origen.

Es decir, que la legislación colombiana tiene un amplio nivel de protección para los migrantes y que es incluso mayor que el regional, por incluir la categoría del numeral (c). A pesar de estos avances respecto a los mundiales, dicha regulación internacional deja por fuera a quienes migran por necesidades económicas, catástrofes ambientales y otras razones, aunque se reconocen nuevos desafíos a raíz del cambio climático y los desastres naturales, como lo hace la Declaración de Brasil (2014).

Como término internacionalmente reconocido para referirse a los migrantes con necesidad de protección internacional (Betts, 2009; Castles, 2003) y a los migrantes económicos (Crisp, 2008), entre otros tipos, se utiliza el de flujos mixtos. Se debe entender que en Colombia los migrantes en situación de protección internacional son los que salvaguarda la
Convención sobre el Estatuto de los Refugiados y los que trae el Decreto 4503 de 2009, en su artículo 1.

Esta Convención debe aplicarse en consonancia con el principio de buena fe (Goodwin-Gill, 2007) y la obligación de abstenerse de realizar cualquier acto que afecte el cumplimiento del tratado. Un acto de entorpecimiento en este sentido sería no recibir una solicitud de refugio, o hacer caso omiso de cualquier información brindada por un migrante que indique que puede estar en situación de protección internacional. Dicho principio no implica para el Estado una limitación en el libre establecimiento de su política migratoria (Goodwin-Gill, 2007), ya que en este punto tiene prevalencia el principio de soberanía del Estado, que le permite limitar el ingreso de extranjeros a su territorio.

La Convención también debe aplicarse sin vulnerar el principio de No devolución, "non-refoulment", para las personas con necesidad de protección internacional (Gil-Bazo, 2015), el cual es de obligatorio cumplimiento por la vía del derecho internacional convencional y el consuetudinario, por ser norma imperativa de ius cogens (Corte Interamericana de Derechos Humanos, 2015). Este principio manifiesta que en ningún caso podrá ser expulsado del país un solicitante de refugio hasta tanto no sea resuelta su solicitud de refugio, si con la expulsión se pone en peligro su vida o integridad personal.

En Colombia las figuras jurídicas de deportación y expulsión están reguladas en 
los Decreto 834 de 2013 "Por el cual se establecen disposiciones en materia migratoria", y 4000 de 2004. La regla general es que opera la figura de deportación ante un ingreso irregular al país; sin embargo, esta medida no procede para el caso de las personas en situación de protección internacional. Es por lo anterior que Migración Colombia como política interna prefiere expulsar al migrante irregular hasta la última frontera cruzada por él mismo y no a su país de origen. Por su parte, la figura de expulsión opera cuando un extranjero haya cometido un delito en territorio colombiano o sea reincidente en su entrada irregular al territorio, entre otras razones.

Las autoridades colombianas, al detectar migrantes que ingresan de manera irregular al territorio, deben entregarlos a la autoridad migratoria, que en nuestro caso es la Unidad Administrativa Especial Migración Colombia, adscrita al Ministerio de Relaciones Exteriores y creada en 2012. Esta entidad también debe estudiar las solicitudes de refugio que reciban de los extranjeros en Colombia, así como expulsar o deportar, de acuerdo con estudio previo de cada caso. Además, tiene como misión combatir los delitos trasnacionales, como el tráfico de migrantes.

En el 2015, Migración Colombia empezó a implementar un Salvoconducto de Deportación por 5 días, como documento temporal de estadía legal, para que en dicho período los migrantes con ingreso irregular al país se devolvieran por sus propios medios hasta la última frontera por la que entraron. En la práctica, los migrantes que obtienen el salvoconducto no se devuelven a la última frontera por la que entraron, sino que siguen la ruta hasta su destino que, para la gran mayoría de los casos, es Estados Unidos. Esta medida empezó a ser implementada ante la imposibilidad presupuestal de expulsar a todos los migrantes que ingresan irregularmente al país o deportarlos a su país de origen.

Desde el análisis teórico realizado, se observa que este instrumento estaría vulnerando el principio de buena fe, y se estaría evadiendo la obligación del Estado de identificar sujetos de protección internacional y recibir solicitudes de refugio, ya que busca que el extranjero abandone el país en el menor tiempo posible. Por otra parte, se identificó que en la práctica se ha convertido en un mecanismo de protección para los migrantes, ante la solicitud repetitiva de sobornos por parte de algunas autoridades para no ser detenidos y entregados a Migración Colombia. También les ha permitido a los migrantes tener un documento temporal de permanencia, con el cual pierden el temor de acudir a las autoridades frente a cualquier violación a sus derechos humanos.

\section{El delito de tráfico de migrantes y la trata de personas}

Según el Protocolo contra el tráfico ilícito de personas por tierra, mar y aire de la Convención de Naciones Unidas contra la Delincuencia Organizada, se define como tráfico ilícito de migrantes "la facilitación de la entrada ilegal de una persona en un Estado parte del cual, dicha persona no sea nacional o residente permanente, 
con el fin de obtener, directa o indirectamente, un beneficio financiero $\mathrm{u}$ otro beneficio de tipo material".

Actualmente, Colombia se encuentra obligada por el Convenio marco contra la Delincuencia Organizada, pero no por el Protocolo específico de protección contra el tráfico ilícito de personas, porque no fue ratificado (Forero Ramírez, 2013). En la práctica esto ha dificultado hacer exigibles sus disposiciones y la creación de una política pública interna que permita la cohesión entre instituciones competentes para la prevención del delito, atención de los migrantes víctimas y persecución penal de las redes internacionales de traficantes.

En el Código Penal colombiano, el delito de tráfico ilícito de migrantes está tipificado como:

El que promueva, induzca, constriña, facilite, financie, colabore o de cualquier otra forma participe en la entrada o salida de personas del país, sin el cumplimiento de los requisitos legales, con el ánimo de lucrarse u obtener cualquier otro provecho para sí u otra persona, incurrirá en prisión de noventa y seis (96) a ciento cuarenta y cuatro (144) meses y multa de sesenta y seis punto sesenta y seis (66.66) a ciento cincuenta (150) salarios mínimos legales mensuales vigentes al momento de la sentencia condenatoria.

Es importante diferenciar este crimen internacional con el de trata de personas, regulado en el Protocolo contra la Trata de Personas, que se deriva de la misma Convención, y sí fue ratificado por Colombia. Según algunos relatos recogidos por las autoridades, las víctimas de tráfico, con cierta frecuencia, se convierten también en víctimas de trata, al ser sometidas a trabajos forzados y/o explotación sexual. Los asiáticos y africanos son especialmente vulnerables a estos tipos de trata porque en algunos casos pagan su viaje con trabajo.

A través de los entes territoriales municipales o departamentales, puede aplicarse la protección de esta población de migrantes traficados que, a su vez, han sido víctimas de trata de personas. Esta protección, mucho más desarrollada que para las víctimas de tráfico ilícito, ha sido lograda por la ratificación e implementación interna del protocolo, lo cual ha permitido que el Gobierno nacional, departamental y local, la Fuerza Pública, la sociedad civil, la academia y las organizaciones internacionales competentes estén coordinados y organizados, y tengan competencias determinadas en la protección de la población víctima. Esto lo han logrado a través de la formulación de rutas de atención, como consecuencia de reuniones periódicas obligatorias en los comités departamentales y municipales de Lucha contra la Trata de Personas.

\section{LAS TENDENCIAS MIGRATORIAS NACIONALES, LOCALES Y LAS RUTAS DE TRÁNSITO}

\section{Las tendencias locales y nacionales}

En el departamento de Antioquia, el flujo mixto de migrantes ha crecido de manera 
exponencial, pasando de 246 personas detectadas -y puestas a disposición de Migración Colombia- por las autoridades en 2012 a 377 en 2013, lo que representa un incremento del $53 \%$, mientras que el aumento de 2013 a 2014 fue del 128\%, alcanzando 861 el número de migrantes. Durante el 2015 fueron detectados en Antioquia 3473 extranjeros que ingresaron al territorio nacional sin el cumplimiento de los requisitos legales (Migración Colombia, 2015), lo que se traduce en un aumento del 303\%.

Hay que aclarar que estas cifras son simples referencias del fenómeno, puesto que la gran mayoría de los migrantes no son detectados, o cuando lo son, ofrecen dinero a las autoridades para que les permitan continuar con su trayecto (Migración Colombia, 2015; Fiscalía General de la Nación, 2015).

En términos nacionales, los migrantes que ingresan irregularmente a Colombia lo hacen principalmente por Ecuador, pero también por Brasil y Venezuela (Migración Colombia, 2015). Estos países, al igual que Panamá, tradicionalmente han tenido leyes migratorias flexibles que permiten el ingreso a su territorio con un permiso o autorización para su tránsito. Esta situación ha cambiado recientemente respecto a Ecuador y Panamá, cuando el primero les impuso visa a los cubanos en diciembre de 2015, y el segundo, cerró su frontera con Colombia el pasado 9 de mayo.

Con respecto a la procedencia de los migrantes que transitan Colombia, 7 de cada
10 son de nacionalidad cubana. Los otros son bangladesíes, pakistaníes, somalíes, nepaleses, eritreos y ganeses, que llegan principalmente por vía aérea o marítima a Brasil (Migración Colombia, 2015). Muchas de estas personas son sujetos de protección internacional, por haber sido objeto de persecución en sus países de origen, haber sufrido situaciones de conflicto interno o violencia generalizada, o haber comenzado a ser objeto de persecución por parte de la red internacional de traficantes durante su viaje (Migración Colombia, 2015).

Históricamente, Colombia no ha tenido vocación de ser un país receptor, y por tanto no tiene una política amplia de soluciones duraderas para refugiados. Las dinámicas propias del conflicto armado interno han generado que sea conocido internacionalmente como expulsor, y que la política pública interna de atención y protección y sus recursos públicos hayan sido destinados para las víctimas de desplazamiento forzado interno. Sin embargo, la vocación del país como no receptor ha ido cambiando con los ciudadanos de países vecinos que buscan refugiarse en un lugar con una cultura similar, a pesar de las limitaciones del programa de refugio colombiano.

Muchas de las personas que componen el flujo migratorio actual y están en situación de protección internacional deciden no pedir refugio en Colombia, porque el Gobierno no brinda ayudas humanitarias a los solicitantes y no otorga permiso temporal de trabajo durante el proceso de estudio de la solicitud (ACNUr, 2015). 
Algunos solicitantes de refugio deciden continuar su viaje, ante la imposibilidad de sostenerse económicamente durante la espera, que puede ser hasta de 6 meses; ya que para recibir las ayudas humanitarias deben haber sido reconocidos como refugiados.

\section{Las rutas}

Los caminos que usan los migrantes para ingresar a Colombia son principalmente rutas de frontera con Ecuador y Venezuela, y en menor medida con Brasil. Por Ecuador ingresan por Ipiales, luego transitan hacia Pasto, Cali, Medellín y Urabá; o utilizan la ruta por el pacífico: por Tumaco, Buenaventura, Bahía Solano y Juradó. También usan en menor medida vías desde Venezuela, que atraviesan la costa atlántica para llegar a Montería y Arboletes.

Otra ruta que recientemente los migrantes cubanos han usado es la de viajar a Guyana en avión, luego pasar a Manaos (Brasil) y cruzar el río Amazonas para llegar a Tabatinga, localidad vecina al municipio de Leticia, para luego llegar a Puerto Asís por la selva, primero del lado de Perú y luego al lado de Colombia por el río Putumayo (CER, 2016).

Cuando llegan a Urabá, utilizan cualquier parte del golfo para salir por el departamento del Chocó hacia Panamá, ya sea por vía fluvial, marítima o terrestre (mapa 1). Desde el Urabá antioqueño y chocoano se desprenden aproximadamente 9 rutas: 2 marítimas y 7 fluviales, y terrestres hacia la frontera con Panamá, que tiene una extensión de $266 \mathrm{~km}$ a lo largo de 4 municipios del departamento de Chocó (Juradó, Riosucio, Unguía, Acandí), que limitan con la provincia del Darién en el lado panameño. Cuando los migrantes usan la vía marítima llegan a Puerto Obaldía en Panamá (ACNUR, 2015).

\section{LOS MIGRANTES, LA RED INTERNACIONAL DE TRAFICANTES Y LOS GRUPOS ARMADOS ILEGALES EN ANTIOQUIA Y CHOCÓ}

Para ejemplificar algunos de los riesgos en materia de garantía de los derechos humanos para los flujos mixtos de migrantes que están siendo traficados en Colombia, este capítulo expone las conexiones entre la red internacional de traficantes, también conocidos como coyotes, y los grupos armados ilegales que hacen presencia o tienen injerencia en algunos lugares del Urabá chocoano y antioqueño.

La red internacional de traficantes está compuesta por personas organizadas y ubicadas en distintos lugares de varios países, que prestan un servicio para facilitar, permitir, conducir, alojar o transportar los migrantes hasta su destino final. Una persona de la red recibe el dinero antes de que el migrante salga del país, y se encarga de pagarle a cada persona que realiza una función durante el trayecto (Migración Colombia, 2015). Migración Colombia ha determinado que los traficantes cobran un promedio de 10 mil dólares a los ciudadanos cubanos, y entre 30 mil y 40 mil a un migrante extra-continental.

Sin embargo, no toda la ruta está cubierta por el pago inicial y puede haber tramos 


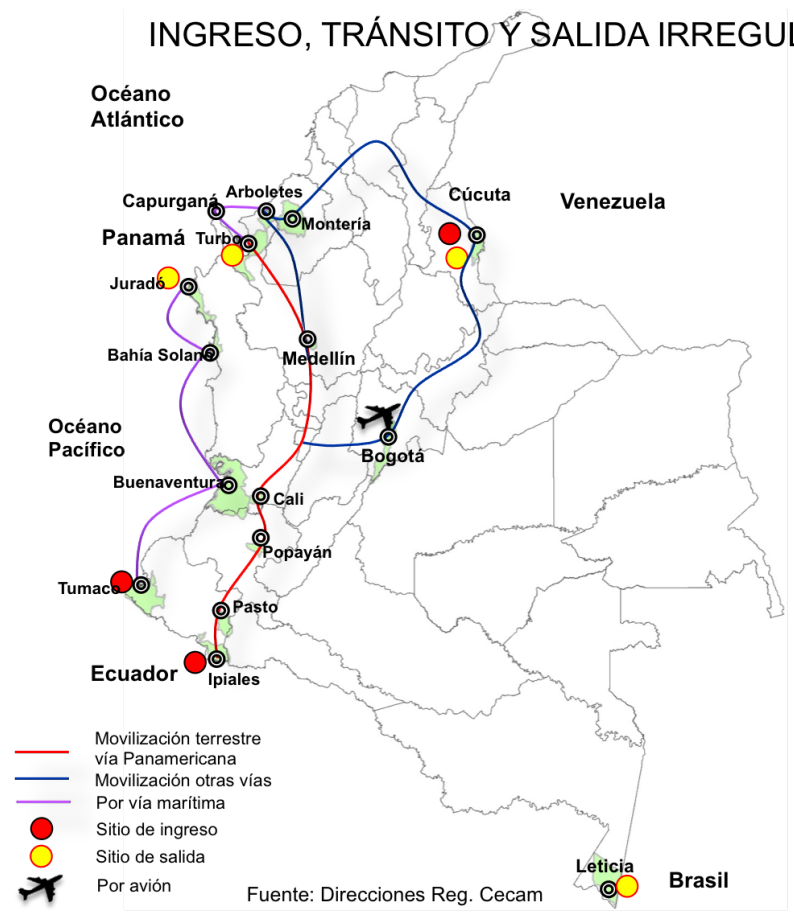

Mapa 1. Ingreso, tránsito y salida irregular de Colombia Fuente: Dirección Reg. Cecam

que el migrante asuma de manera independiente, y personas que se involucren en el tráfico sin que estén conectadas con la red internacional, como los hoteles, algunos transportadores, y personas que alojan y sirven de guías en las selvas chocoanas y panameñas.

De acuerdo con las entrevistas realizadas, se pudo determinar que la guerrilla FARCEP no tiene ningún tipo de relación directa con la red internacional. Sin embargo, en algunos casos cobran para guiar a los migrantes cuando realizan la ruta terrestre que cruza el Chocó y la selva del Darién para llegar a Panamá. Adicionalmente, son quienes autorizan qué personas de las comunidades locales pueden servir de guías. Y hace aproximadamente dos años, les exigían a los migrantes pasar estupefacientes hasta Panamá -cuando hacían la ruta terrestre a través de Acandí-, como una forma de contraprestación por permitirles el tránsito a través de sus territorios de influencia; pero frenaron esta práctica por los riesgos que asumían (Migración Colombia, 2015).

La banda criminal "El Clan Úsuga", que es un grupo posdesmovilización de las autodefensas, realiza un control sobre el tráfico de migrantes, pero tampoco está relacionado con la red internacional. En pocas ocasiones han efectuado el tráfico 
de manera directa, y su control se ha limitado a cobrar extorsiones a los migrantes para permitirles transitar hasta el Darién chocoano, sobre todo para abordar las lanchas y pangas que salen desde Necoclí, Turbo y el río Atrato.

En el 2015 en la subregión de Urabá, el "Clan Úsuga" les ordenó a los traficantes, conocidos como coyotes, no utilizar sus rutas marítimas de narcotráfico para el tráfico de migrantes. A su vez, al gremio hotelero le ordenó no alojar migrantes, porque estaban llamando la atención de las autoridades. Por esta razón, la ruta por el bajo Atrato chocoano, que es más larga, costosa y peligrosa por ser selvática, está siendo frecuentemente usada.

Esta orden del "Clan Úsuga" no fue del todo acatada, pues algunos hoteles continuaron alojando a migrantes. Sin embargo, actualmente la mayoría es hospedada en viviendas en Turbo y Necoclí, muchas de estas al borde del mar. Desde allí zarpan en lanchas por las noches, desconociendo la restricción de navegación durante la noche debido a la alta marea, y en algunos casos también la de seguridad, por el no uso de chalecos salvavidas. La Armada Nacional ha reportado casos de rescates que han realizado de embarcaciones en peligro de sumergimiento, en donde los rescatados han sido extranjeros sin documentación y con ingreso legal al país.

El paso por Colombia es uno de los tramos más costosos para los migrantes, a causa de la restrictiva política migratoria que incrementa los costos que cobra la red internacional y el pago de sobornos a algunas autoridades que lo permiten. Los migrantes quedan en una situación de desprotección frente a las acciones ilegales que ejercen sobre ellos los grupos armados y la criminalidad organizada, debido a su situación irregular y al temor de acercarse a las autoridades. Existen testimonios en que los migrantes que ya han llegado a México o Estados Unidos relatan el paso por Colombia como uno de los más peligrosos (Cinta, 2015). Otros tramos de la ruta que son peligrosos para sus vidas son el cruce en lancha del golfo de Urabá -ya que lo hacen de noche, sin salvavidas, con marea alta y sobrecupo-y el cruce por la selva del Darién -por los animales salvajes y un clima húmedo y cálido que dificulta su paso-.

Esta situación de extrema vulnerabilidad le impone al Estado retos que implican la implementación de estrategias distintas de investigación y elaboración de planes metodológicos en las investigaciones penales por el delito de tráfico de migrantes, como por los múltiples delitos que tipifican las vulneraciones a los derechos humanos que sufren durante su trayecto por Colombia.

\section{CONCLUSIONES Y RECOMENDACIONES DESDE EL ENFOQUE DEL DERECHO INTERNACIONAL DE REFUGIADOS}

Las tendencias mundiales y nacionales sobre flujos migratorios indican que Colombia se ha convertido en un país de tránsito para migrantes en condición de protección internacional, y otras personas que tienen motivaciones distintas a las 
reguladas por el derecho internacional de los refugiados, como el caso de quienes emigran por razones económicas o catástrofes ambientales. Estos últimos se presentan como un nuevo desafío del cambio climático, cuya condición posiblemente comience a ser regulada bajo una categoría independiente denominada "refugiados ambientales".

Aproximadamente, el $70 \%$ de los flujos mixtos de migrantes que cruzan Colombia con el objetivo de llegar a Estados Unidos lo componen personas de nacionalidad cubana. En esta problemática se tienen en cuenta varios aspectos, entre ellos que Estados Unidos es el segundo Estado industrializado con mayor cantidad de solicitudes de refugio en el mundo, después de Alemania (UNHCR, 2015). Por otra parte, la diáspora cubana ha estado caracterizada y promovida por la Ley de Ajuste Cubano, expedida por Estados Unidos en 1966, y por la Política Pies Mojados/Pies Secos. Sin embargo, el aumento de las dinámicas migratorias recientes se debe a los acercamientos entre los mandatarios de estos dos países, la regularización de sus relaciones diplomáticas y el temor de la finalización de los beneficios en materia de refugio, que han sido medidas diplomáticas adoptadas por Estados Unidos como presión y rechazo al gobierno de Fidel Castro.

A partir del análisis de los perfiles de estos flujos mixtos de migrantes continentales y extra-continentales que cruzan Colombia, y de la normativa internacional mundial y regional, se concluye que la mayoría de estas personas son sujetos de protección internacional, con las prerrogativas que les otorga la Convención sobre el Estatuto para los Refugiados y el Protocolo de 1967. En este orden de ideas, es imperativo que, frente a los migrantes irregulares que son detectados por las autoridades nacionales, siempre se aplique el principio de no-devolución, el cual es costumbre internacional y como tal es norma de ius cogens y, en consecuencia, es de obligatorio cumplimiento.

Este imperativo de no-devolución debe ser aplicado en conjunto con el principio de buena fe, que implica que las autoridades no realicen ningún acto de entorpecimiento en caso de recibir cualquier información por parte del extranjero que indique estar en una situación de protección internacional. La buena fe exige en dichos casos explicarles a estos migrantes que tienen derecho a pedir refugio en Colombia si así voluntariamente lo desean hacer. El principio de buena fe y el derecho internacional de refugiados también le imponen al Estado la obligación de proteger a las personas que no quieran acogerse al refugio bajo la ley nacional y quieran hacerlo en otro país, como es el caso de Estados Unidos.

Colombia, en ejercicio de su poder soberano, adoptó una política migratoria mucho más restrictiva que la de sus países vecinos que, si bien está amparada en el derecho internacional, debe ser analizada en su contexto y de acuerdo con las obligaciones adquiridas en materia de derechos humanos por la ratificación de diversos tratados. En este sentido, las tendencias globales y los fenómenos de- 
lictivos trasnacionales, como el tráfico de personas, han convertido a nuestro país en un lugar peligroso y oneroso para los migrantes.

Las violaciones de derechos humanos que se están cometiendo contra esta población migrante se derivan del estado de desprotección generado por su tránsito irregular por el país, lo cual está dejando a los flujos mixtos en una situación de extrema vulnerabilidad y revictimización frente a la red internacional de traficantes, los grupos armados ilegales y algunos agentes del Estado que han aceptado, o solicitado, dádivas y sobornos. Por estos motivos, es necesario implementar medidas que mejoren la situación de vulnerabilidad de dicha población, como la visa de tránsito y/o visa o permiso humanitario, que no implican un cambio radical de la política migratoria asumida por el Gobierno colombiano.

Estas visas ofrecen una verdadera protección jurídica inicial para los flujos mixtos, si se comparan con el Salvoconducto de Deportación, que desde un análisis jurídico no cumple con el propósito para el que fue creado y desconoce el principio de buena fe, obligatorio para las personas en situación de protección internacional.

Las dinámicas globales ameritan la conformación de una mesa de trabajo con el objetivo de articular las autoridades de control, elaborar las rutas de atención y distribuir las responsabilidades frente a la alimentación, refugio, transporte y servicios de salud de los migrantes, tal como se ha desarrollado la protección para las víctimas de trata de personas. Las rutas deben ser elaboradas de acuerdo con los perfiles de los flujos mixtos, es decir, diferenciando entre sujetos con necesidad de protección internacional (por la vía de la Convención sobre el Estatuto de los Refugiados), solicitantes de refugio o migrantes en tránsito, entre otras posibilidades.

A su vez, es indispensable fortalecer los procesos de investigación penal frente a los eventos de corrupción y otros delitos cometidos contra migrantes, porque constituyen graves violaciones a los derechos humanos. Si Colombia ratificara el protocolo contra el tráfico ilícito de personas de la Convención de Naciones Unidas contra la Delincuencia Organizada, brindaría un impulso en esta vía.

Por último, es necesario prepararnos para el posconflicto y proyectar la transición de Colombia como país expulsor a uno receptor, según lo sugiere el análisis de las tendencias globales. Para esto es importante generar un debate, tanto frente al manejo que se le debe dar al asilo como frente a la construcción de una política pública de soluciones duraderas para los refugiados de otros países, y para los colombianos que retornen como consecuencia del acuerdo de paz. En este sentido, la Declaración de Brasilia sobre la Protección de Personas Refugiadas y Apátridas en el Continente Americano (2014) brinda la ruta de navegación requerida para la implementación de soluciones nacionales y regionales innovadoras, tal y como ha sido caracterizada la iniciativa americana en el manejo del asilo. 


\section{REFERENCIAS BIBLIOGRÁFICAS}

Betts, A. (2009). Forced migration and global politics. Chichester: Wiley-Blackwell.

Casanovas, O. E Rodrigo Hernández, A. (2012). Compendio de derecho internacional público. Madrid: Tecnos.

Castles, S (2003). The international politics of forced migration. Development, 46 (3), 11-20.

Cinta. (2015, 25 de septiembre). ¿Qué sucede en África en pleno siglo XXI?: Detonantes de la migración de origen africano en tránsito por Tapachula, Chiapas. En II Congreso Internacional: Migración Internacional en América Latina y México en el contexto de la crisis económica y humanitaria. Evento realizado en Ciudad de México, México.

Coloquio sobre la Protección Internacional de los Refugiados en América Central, México y Panamá. (1984). Declaración de Cartagena adoptada por el Coloquio sobre la Protección Internacional de los Refugiados en América Central, México y Panamá: Problemas jurídicos y humanitarios. Cartagena, Colombia.

Congreso de la República Colombia. (1961). Ley 35 del 12 de 1961 por la cual se aprueba la Convención sobre el Estatuto de Refugiados. Bogotá: Congreso de la Republica de Colombia.

(2000). Ley 599 del 24 de julio de 2000, por la cual se expide el Código Penal. Bogotá: Congreso de la República.

(2004). Ley 800 del 13 de marzo de 2004, por medio de la cual se aprueba la Convención de las Naciones Unidas contra la delincuencia organizada trasnacional y el protocolo facultativo para prevenir, reprimir y sancionar la trata de personas, especialmente mujeres y niños. Bogotá: Congreso de la República Colombia.

Corte Interamericana de Derechos Humanos. (2015). Cuadernillo: Migrantes. En Jurispru- dencia de la Corte Interamericana de Derechos Humanos. San José, Costa Rica: CrIDH con la colaboración de Claudio Nash y el Ministerio de Relaciones Exteriores de Dinamarca. Recuperado a partir de http://www.corteidh. or.cr/sitios/libros/todos/docs/migrantes4.pdf

Crisp, J. (2003). A new asylum paradigm? Globalisation, migration and the uncertain future of the international refugee regime. New Issues in Refugee Research Working Paper 100.

Discussion Document UNHCR November 2004. (2006). The Refugee Situation in Latin America: Protection and Solutions Based on the Pragmatic Approach of the Cartagena Declaration on Refugees of 1984. International Journal of Refugee Law, 18 (1), 252-270. http:// doi.org/10.1093/ijrl/eei042

Fiscalía General de la Nación (2015). Entrevista realizada a agente del CTI de la Sala de Análisis Criminal de la Fiscalía. Medellín, Colombia.

Frontex. (2015, 18 de agosto). Number of migrants in one month above 100000 for first time, Frontex. Visto el 10 de septiembre 2015, http://frontex.europa.eu/news/number-ofmigrants-in-one-month-above-100-000-forfirst-time-I9Mllo.

Gil-Bazo, M.-T. (2015). Refugee Protection under International Human Rights Law: From NonRefoulement to Residence and Citizenship. Refugee Survey Quarterly, 34 (1), 11-42. http:// doi.org/10.1093/rsq/hdu021

Gil-Bazo, M. E Nogueira, M. (2013). El asilo en la práctica de los Estados de América Latina y África. Nuevos temas en la investigación sobre refugiados, (Informe de investigación No. 249).

Gobiernos participantes de América Latina y del Caribe. (2014). Declaración de Brasil "Un Marco de Cooperación y Solidaridad Regional para Fortalecer la Protección Internacional de las Personas Refugiadas, Desplazadas y Apátridas en América Latina y el Caribe". Brasil. 
Goodwin-Gill, G. (2007). The refugee in international law. Oxford; New York: Oxford University.

La Comisión sobre Migraciones Forzadas, Exilio y Reconciliación -CER-. (2016). Informe de ca (2010). Declaración de Brasilia Sobre la Protección de Personas Refugiadas y Apátridas en el Continente Americano, 1-4. Retrieved from http://www.acnur.org/biblioteca/ pdf/8133.pdf?view=1.
. (2015). Entrevista realizada una funcionaria de ACNUR en la oficina de Apartadó - Antioquia. Apartadó, Colombia.

(2016). Tendencias globales: Desplazamiento forzado en 2015. Ginebra. Retrieved from http://www.acnur.org/fileadmin/scripts/ doc.php?file=fileadmin/Documentos/Publicaciones/2016/10627. 